\title{
Interface Characterization of Cobalt Contacts on Bismuth Selenium Telluride for Thermoelectric Devices
}

\author{
R. P. Gupta, ${ }^{a}$ O. D. Iyore, ${ }^{a}$ K. Xiong, ${ }^{a}$ J. B. White, ${ }^{\text {b }}$ Kyeongjae Cho, ${ }^{\text {a, }}$ \\ H. N. Alshareef, and B. E. Gnade ${ }^{\mathrm{a}, \mathrm{z}}$ \\ ${ }^{a}$ Department of Material Science and Engineering, University of Texas at Dallas, \\ Richardson, Texas 75080, USA \\ ${ }^{b}$ Marlow Industries Incorporated, a subsidiary of II-VI Incorporated, Dallas, Texas 75238, USA \\ ${ }^{c}$ Material Science and Engineering, King Abdullah University of Science and Technology, \\ Thuwal, 23955-6900 Saudi Arabia
}

Sputtered $\mathrm{Co}$ is investigated as a suitable contact metal for bulk $\mathrm{Bi}_{2}(\mathrm{Te}, \mathrm{Se})_{3}$, and the results are compared to sputtered $\mathrm{Ni}$. The coefficient of thermal expansion of Co matches that of bulk $\mathrm{Bi}_{2}(\mathrm{Te}, \mathrm{Se})_{3}$ used in our study, and the compatible interface favors the selection of $\mathrm{Co}$ as a contact metal. Significant Ni diffusion into $\mathrm{Bi}_{2}(\mathrm{Te}, \mathrm{Se})_{3}$ was observed. In contrast, $\mathrm{Co}$ on $\mathrm{Bi}{ }_{2}(\mathrm{Te}, \mathrm{Se})_{3}$ shows significantly less diffusion, even at anneal temperatures as high as $200^{\circ} \mathrm{C}$. $\mathrm{CoTe}_{2}$ is the preferred phase that is formed. First principles calculations for $\mathrm{Bi}_{2} \mathrm{Te}_{3}$ support the experimental observation. (C) 2009 The Electrochemical Society. [DOI: 10.1149/1.3196237] All rights reserved.

Manuscript submitted May 22, 2009; revised manuscript received July 14, 2009. Published August 13, 2009.

Thermoelectric (TE) coolers have been extensively used in the optoelectronic, automotive, space, and semiconductor industries where low device operational temperature is a key to the device performance in terms of speed and reliability. ${ }^{1}$ Plated Ni has been used as a barrier metal between $\mathrm{Cu}$ and both $\mathrm{p}$ - and n-type bismuthtelluride-based thermoelements. The contact resistivity between plated $\mathrm{Ni}$ and $\mathrm{Bi}_{2}(\mathrm{Te}, \mathrm{Se})_{3}$ was measured to be approximately 5 $\times 10^{-6} \Omega \mathrm{cm}^{2}$, which is about 1 order of magnitude higher than needed for next generation, small TE coolers. ${ }^{3}$ A process was developed to reduce the contact resistance by at least 10 times with sputtered $\mathrm{Ni}$ as the contact metal on bulk $\mathrm{Bi}_{2}(\mathrm{Te}, \mathrm{Se})_{3}$. However, while sputtered Ni provides low contact resistivity, it shows significant diffusion into the TE material after annealing at $200^{\circ} \mathrm{C}$. $^{4}$ The $\mathrm{Ni}$ diffusion appears to degrade the TE properties of the TE material, resulting in poor cooler performance. ${ }^{5}$ In this study, we present the interface characterization of sputtered $\mathrm{Co}$ on bulk $\mathrm{Bi}_{2}(\mathrm{Te}, \mathrm{Se})_{3}$ and compare the results to sputtered $\mathrm{Ni}$ films. The coefficient of thermal expansion of $\mathrm{Co}$ matches that of bulk $\mathrm{Bi}_{2}(\mathrm{Te}, \mathrm{Se})_{3}$, making it a good candidate for a contact metal.

An AJA ATC Orion 4 HV Magnetron system was used to sputter $\mathrm{Ni}$ and $\mathrm{Co}$ onto polycrystalline $\mathrm{Bi}_{2}(\mathrm{Te}, \mathrm{Se})_{3}$. The substrates were rinsed with acetone, isopropyl alcohol, and deionized water before loading in the deposition system. The substrates were sputtercleaned with $\mathrm{Ar}^{+}$in situ before deposition to remove surface contaminants and native oxide. The $\mathrm{Co}$ and $\mathrm{Ni}$ films were sputtered for 10 and $15 \mathrm{~min}$ at room temperature, respectively, at a vacuum pressure of $4 \mathrm{mTorr}$ and a power density of $10 \mathrm{~W} / \mathrm{cm}^{2}$. The thicknesses obtained for $\mathrm{Ni}$ and Co were 120 and $90 \mathrm{~nm}$, respectively, as measured using a cross sectional scanning electron microscopy image.

The interfacial characterization of the samples was carried out using a JEOL $2100 \mathrm{~F}$ transmission electron microscope (TEM) operated at $200 \mathrm{kV}$. Cross-sectional specimens for TEM analysis were prepared using a lift-out technique with an FEI Nova 200 dual column focused ion beam (FIB)/scanning electron microscopy system. This technique avoids dimpling difficulties and thermal exposure artifacts of the traditional polishing procedure for this material. A $3 \mu \mathrm{m}$ thick Pt film was deposited in situ using an organometallic precursor for protection of the Co film during the sample preparation, and FIB polishing parameters were optimized for the soft TE material.

Grazing incidence X-ray diffraction (GIXRD) was used for the structural characterization of the as-deposited and annealed films using a Rigaku ULTIMA III system with $\mathrm{Cu} \mathrm{K} \alpha(\lambda=1.54 \AA)$

\footnotetext{
*lectrochemical Society Active Member

z E-mail: gnade@utdallas.edu
}

X-ray radiation operated at $40 \mathrm{kV}$ and $44 \mathrm{~mA}$. GIXRD uses a small incident angle for the incoming $\mathrm{X}$-rays so that the diffraction is surface sensitive, minimizing the contribution from the substrate. A thin film can be probed through its thickness by varying the angle of incidence to obtain depth-resolved information about the structure and the interfaces. ${ }^{6,7}$

GIXRD revealed the presence of $\mathrm{CoTe}_{2}$ at the interface for the $90 \mathrm{~nm}$ sputtered Co film annealed at $200^{\circ} \mathrm{C}$ for $1 \mathrm{~h}$. No other $\mathrm{Co}_{x} \mathrm{Te}_{y}$ phases were observed for the as-deposited sample, as seen in Fig. 1. Figure 1 also compares the X-ray diffraction (XRD) pattern for the sputtered Co sample annealed at $200^{\circ} \mathrm{C}$ in $\mathrm{N}_{2}$ for $\omega=0.5,1$, and $2^{\circ}$ where $\omega$ is the angle of incidence for the X-ray beam. The X-rays penetrate further into the sample as the angle of incidence is increased. No CoTe $e_{2}$ peaks are seen at $\omega=0.5^{\circ}$, which suggests that the $\mathrm{CoTe}_{2}$ is not on the film surface but only at the interface. The $\mathrm{CoTe}_{2}$ peaks agree with Borstigen and Kjekshus, ${ }^{8}$ where the crystal structure for $\mathrm{CoTe}_{2}$ is orthorhombic belonging to the Pnn2 (34) space group with cell dimensions $a=5.3 \AA, b=6.3 \AA$, and $c$ $=3.9 \AA\left(\alpha=90^{\circ}, \beta=90^{\circ}\right.$, and $\left.\gamma=90^{\circ}\right)$ while Co is hexagonal with cell dimensions $a=2.5 \AA, b=2.5 \AA$, and $c=4.1 \AA(\alpha$ $=90^{\circ}, \beta=90^{\circ}$, and $\gamma=120^{\circ}$ ), and space group P63/mmc (194). ${ }^{9}$ Ko et al. showed that a sputtered Co film deposited at room tem-

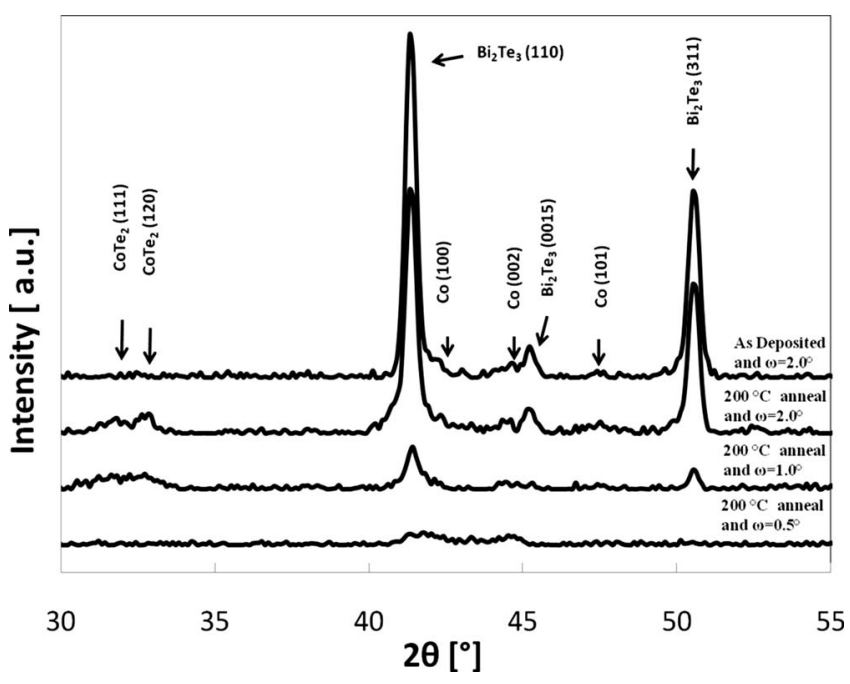

Figure 1. XRD spectra for the as-deposited $90 \mathrm{~nm}$ sputtered Co film taken at an X-ray incidence angle of $\omega=2^{\circ}$ and annealed film at $200^{\circ} \mathrm{C}$ for $\omega$ $=0.5,1.0$, and $2.0^{\circ}$. 


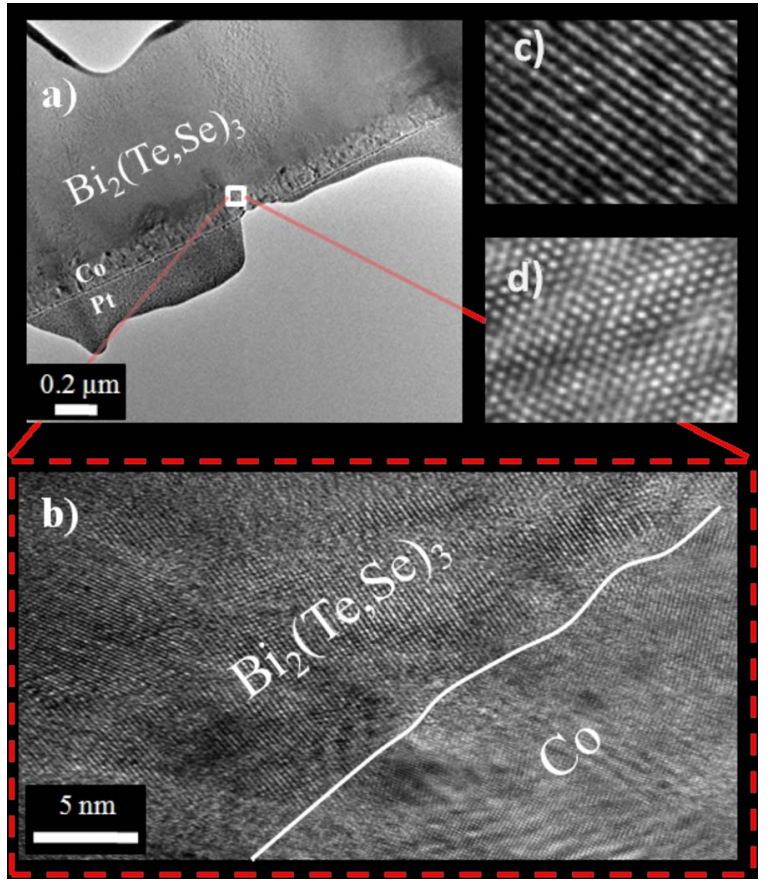

Figure 2. (Color online) (a) TEM image of $90 \mathrm{~nm}$ sputtered Co film on $\mathrm{Bi}_{2} \mathrm{Te}_{3}$ annealed at $200^{\circ} \mathrm{C}$. (b) High resolution image of the interface region between $\mathrm{Co}$ and $\mathrm{Bi}_{2} \mathrm{Te}_{3}$. (c) Lattice image of the $\mathrm{Bi}_{2} \mathrm{Te}_{3}$ area showing $\mathrm{Bi}-\mathrm{Te}$ stack lines. (d) Lattice image of the Co region showing the hexagonal crystal atomic sites.

perature on $\mathrm{Si}(100)$ is amorphous and becomes crystalline when annealed at $300^{\circ} \mathrm{C} .{ }^{10}$ The XRD data on as-deposited sputtered Co show a similar trend and are weakly crystalline. Co is also known to change phase from $\alpha$-Co (hexagonal close-packed) to $\beta$-Co (facecentered cubic) at $380^{\circ} \mathrm{C} .{ }^{11}$ For the TE material that has hexagonal symmetry, $\alpha$-Co would be preferred. The TEM image in Fig. 2 shows no diffusion for sputtered $\mathrm{Co}$ on $\mathrm{Bi}_{2}(\mathrm{Te}, \mathrm{Se})_{3}$ annealed at $200^{\circ} \mathrm{C}$. A sharp interface, on the order of the roughness of the substrate $R_{\mathrm{a}} \sim 4 \mathrm{~nm}$, can be observed, which agrees with the GIXRD results.

Figure 3 shows XRD spectra with an X-ray incidence angle of $\omega=2^{\circ}$ for sputtered $\mathrm{Ni}$ films on $\mathrm{Bi}_{2}(\mathrm{Te}, \mathrm{Se})_{3}$ after different annealing temperatures. In contrast to the sputtered Co films, Ni shows

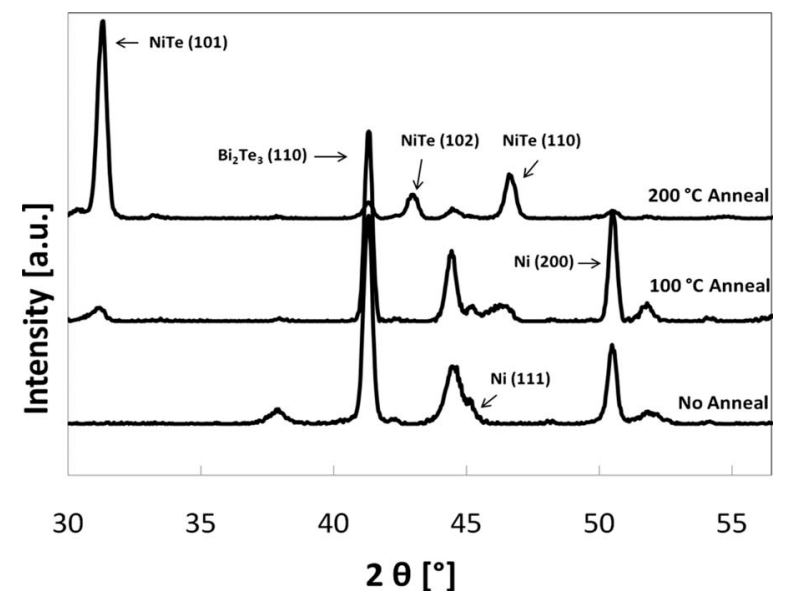

Figure 3. XRD spectra taken at an X-ray incidence angle of $\omega=2^{\circ}$ comparing $120 \mathrm{~nm}$ sputtered $\mathrm{Ni}$ film for as-deposited, $100^{\circ} \mathrm{C}$, and $200^{\circ} \mathrm{C}$ annealed samples.

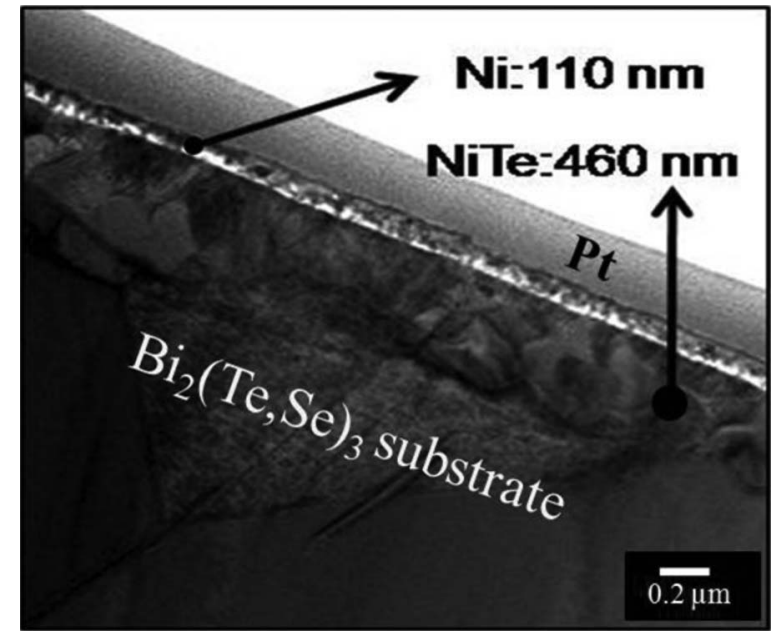

Figure 4. TEM image of $120 \mathrm{~nm}$ sputtered $\mathrm{Ni}$ on $\mathrm{Bi}_{2} \mathrm{Te}_{3}$ annealed at $200^{\circ} \mathrm{C}$ showing $460 \mathrm{~nm}$ of diffused NiTe region.

strong diffraction peaks indicative of a crystalline structure even for the as-deposited film and NiTe forms at anneal temperatures as low as $100^{\circ} \mathrm{C}^{2}$ The intensity of the NiTe(101) peak for the sample annealed at $200^{\circ} \mathrm{C}$ is proportional to the thickness of the NiTe layer that is formed. The cross-sectional TEM image of the same sample shows a $460 \mathrm{~nm}$ diffused region, as seen in Fig. 4.

To understand the stability of $\mathrm{Ni}$ and $\mathrm{Co}$ on bulk $\mathrm{Bi}_{2}(\mathrm{Te}, \mathrm{Se})_{3}$, we performed first principles calculations on pure $\mathrm{Bi}_{2} \mathrm{Te}_{3}$ to study $\mathrm{Ni} / \mathrm{Bi}_{2} \mathrm{Te}_{3}$ and $\mathrm{Co} / \mathrm{Bi}_{2} \mathrm{Te}_{3}$ interfaces using the total energy planewave basis code VASP. ${ }^{12}$ The calculated enthalpies of the formation of bulk NiTe, CoTe, $\mathrm{NiTe}_{2}$, and $\mathrm{CoTe}_{2}$ are $-0.4,-0.17,-0.72$, and $-0.64 \mathrm{eV}$, respectively, indicating that $\mathrm{Ni}$ tellurides are more stable than Co tellurides. The formation energies for incorporating Te and $\mathrm{Bi}$ into bulk $\mathrm{Co}$ are -1.05 and $-2.65 \mathrm{eV}$, respectively. For comparison, the formation energies for incorporating Te and $\mathrm{Bi}$ into bulk $\mathrm{Ni}$ are higher than the Co case, are 0.64 and $1.99 \mathrm{eV}$, respectively. We now consider the $\mathrm{Ni} / \mathrm{Bi}_{2} \mathrm{Te}_{3}$ and $\mathrm{Co} / \mathrm{Bi}_{2} \mathrm{Te}_{3}$ interfaces. For each metal, two types of interfaces were considered: $\mathrm{Bi}$ terminated and $\mathrm{Te}$ terminated. The relative stability of these interfaces is determined by calculating their interface formation energies. Figure 5 shows the

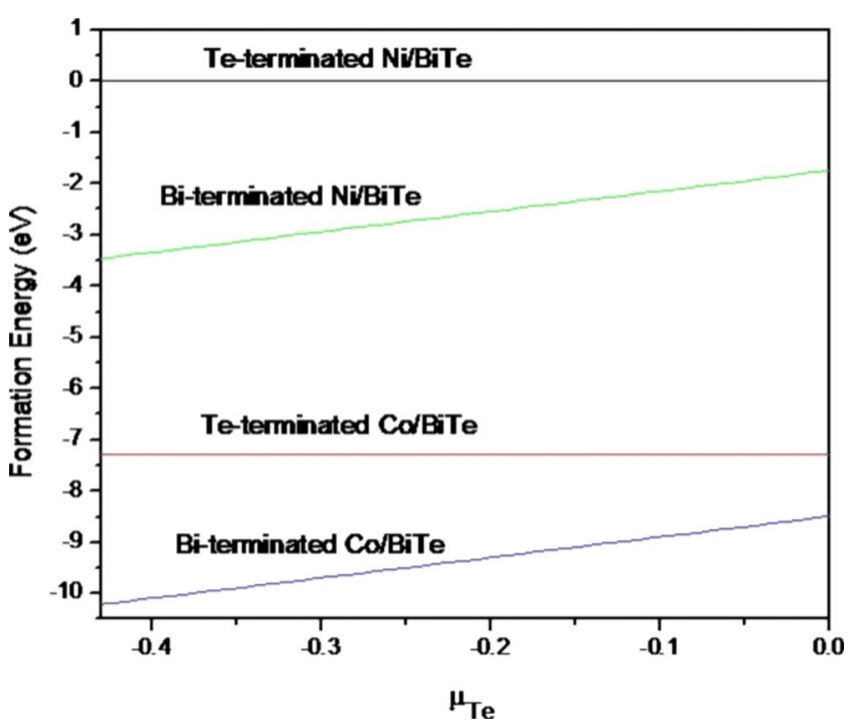

Figure 5. (Color online) Quantum simulation result showing interface formation energy of various interfaces as a function of Te chemical potential. 
interface formation energy of $\mathrm{Ni} / \mathrm{Bi}_{2} \mathrm{Te}_{3}$ and $\mathrm{Co} / \mathrm{Bi}_{2} \mathrm{Te}_{3}$ interfaces as a function of Te chemical potential, relative to the formation energy of the Te-terminated $\mathrm{Ni} / \mathrm{Bi}_{2} \mathrm{Te}_{3}$ interface. It shows that for each metal, the Bi-terminated interfaces have lower interface formation energy than the Te-terminated interfaces. More importantly, the formation energies for $\mathrm{Co} / \mathrm{Bi}_{2} \mathrm{Te}_{3}$ interfaces are much lower than $\mathrm{Ni} / \mathrm{Bi}_{2} \mathrm{Te}_{3}$ interfaces by approximately $7 \mathrm{eV} .{ }^{13}$ This may explain why $\mathrm{Ni}$ interacts more readily with $\mathrm{Bi}_{2} \mathrm{Te}_{3}$ to form a thick NiTe interfacial region, while $\mathrm{Co}$ does not. The formation of the $\mathrm{Ni} / \mathrm{Bi}_{2} \mathrm{Te}_{3}$ interface is less energetically expensive so that $\mathrm{Ni}$ tends to diffuse into $\mathrm{Bi}_{2} \mathrm{Te}_{3}$ to form an interface with lower energy.

In conclusion, we have shown the interfacial reaction of sputtered $\mathrm{Co}$ and $\mathrm{Ni}$ with bulk $\mathrm{Bi}_{2}(\mathrm{Te}, \mathrm{Se})_{3}$ during low temperature anneals. The dominant phases formed were $\mathrm{CoTe}_{2}$ and $\mathrm{NiTe}$ for Co and $\mathrm{Ni}$, respectively. At $200^{\circ} \mathrm{C} \mathrm{Ni}$ tends to diffuse into the substrate, while no such diffusion was observed for Co films. Quantum simulations substantiate this observed diffusion. The simulations show that $\mathrm{Co}$ forms a more stable interface with $\mathrm{Bi}_{2} \mathrm{Te}_{3}$, while Ni tends to diffuse into the substrate to lower its energy state. The minimal diffusion of Co implies that the TE material should not degrade at high device operating temperatures. Work is in progress on measuring contact resistance of sputtered $\mathrm{Co}$ on thin-film $\mathrm{Bi}_{2} \mathrm{Te}_{3}$ after different postanneal temperatures. Initial results show that sputtered Co gives comparable contact resistance to sputtered $\mathrm{Ni}$, while providing a more stable interface.

\section{Acknowledgments}

The authors thank the II-VI Foundation, a private foundation, for their financial support of this work. Dr. Dongkyu Cha and Taehun
Lee provided valuable help on TEM imaging and analysis. Dr. Jeff Sharp of Marlow Industries provided valuable input to the data analysis and interpretation.

University of Texas at Dallas assisted in meeting the publication costs of this article.

\section{References}

1. V. Semenyuk, in Proceedings of the 22nd International Conference on Thermoelectrics, IEEE, p. 631 (2003).

2. R. P. Gupta, J. B. White, O. D. Iyore, U. Chakrabarti, H. N. Alshareef, and B. E. Gnade, Electrochem. Solid-State Lett., 12, H302 (2009).

3. V. Semenyuk, in Proceedings of the 20th International Conference on Thermoelectrics, IEEE, p. 391 (2001).

4. O. D. Iyore, T. H. Lee, R. P. Gupta, J. B. White, H. N. Alshareef, M. J. Kim, and B. E. Gnade, Surf. Interface Anal., 41, 440 (2009).

5. Y. C. Lan, D. Z. Wang, G. Chen, and Z. F. Ren, Appl. Phys. Lett., 92, 101910 (2008)

6. P. Colombi, P. Zanola, E. Bontempi, R. Roberti, M. Gelfi, and L. Depero, J. Appl. Crystallogr., 39, 176 (2006).

7. J. Kim, E. Ryba, and J. Bai, Polymer, 44, 6663 (2003)

8. G. Brostigen and A. Kjekshus, Acta Chem. Scand. (1947-1973), 24, 1925 (1970).

9. L. J. E. Hofer and W. C. Peebles, J. Am. Chem. Soc., 69, 893 (1947)

10 Y. K. Ko, D. S. Park, B. S. Seo, H. J. Yang, H. J. Shin, J. Y. Kim, J. H. Lee, W. H. Lee, P. J. Reucroft, and J. G. Lee, Mater. Chem. Phys., 80, 560 (2003).

11. C. Cabral, Jr., K. Barmak, J. Gupta, L. A. Clevenger, B. Arcot, D. A. Smith, and J. M. E. Harper, J. Vac. Sci. Technol. A, 11, 1435 (1993).

12. G. Kresse and J. Furthmuller, Comput. Mater. Sci., 6, 15 (1996); G. Kresse and J. Furthmuller, Phys. Rev. B, 54, 11169 (1996).

13. K. Xiong, W. Wang, H. N. Alshareef, R. P. Gupta, B. E. Gnade, and K. Cho, Mater Res. Soc. Symp. Proc., 1166, N05 (2009). 